\title{
The relationship between attention allocation and cheating
}

\author{
Andrea Pittarello $^{1} \cdot{\text { Daphna } \text { Motro }^{2} \text { - Enrico Rubaltelli }}^{3,4} \cdot$ Patrik Pluchino $^{3}$
}

Published online: 4 September 2015

(C) Psychonomic Society, Inc. 2015

\begin{abstract}
Little is known about the relationship between attention allocation and dishonesty. The goal of the present work was to address this issue using the eyetracking methodology. We developed a novel task in which participants could honestly report seeing a particular card and lose money, or they could falsely report not seeing the card and not lose money. When participants cheated, they allocated less attention (i.e., shorter fixation durations and fewer fixations) to the card than when they behaved honestly. Our results suggest that when dishonesty pays, shifting attention away from undesirable information can serve as a self-deception strategy that allows individuals to serve their self-interests while maintaining a positive self-concept.
\end{abstract}

Keywords Eyetracking $\cdot$ Behavioral ethics $\cdot$ Attention · Unethical behavior

Electronic supplementary material The online version of this article (doi:10.3758/s13423-015-0935-z) contains supplementary material, which is available to authorized users.

Andrea Pittarello

andre.pittarello@gmail.com

$\triangle$ Daphna Motro

dmotro@email.arizona.edu

1 Psychology Department, Ben-Gurion University of the Negev, Beer-Sheva, Israel

2 Department of Management and Organizations, University of Arizona, Tucson, AZ, USA

3 Department of Developmental and Socialization Psychology, University of Padua, Padua, Italy

4 Cognitive Neuroscience Center, University of Padua, Padua, Italy
When facing ethical dilemmas, individuals often balance two competing desires: serving their self-interests and upholding their moral standards (Mazar, Amir, \& Ariely, 2008). Recent work has shown that individuals often resolve this ethical dilemma (Barkan, Ayal, Gino, \& Ariely, 2012) by employing self-deception strategies (Tenbrunsel \& Messick, 2004), such as moral disengagement and rationalization (Shu, Gino, \& Bazerman, 2011; Zhong, 2011). These strategies allow reaping the benefits of dishonesty while avoiding the negative repercussions that stem from bending the rules. To date, most research has investigated the contextual factors associated with self-deception, such as the availability of justifications (Pittarello, Leib, Gordon-Hecker, \& Shalvi, 2015; Shalvi, Dana, Handgraaf, \& De Dreu, 2011) and the presence of visual reminders of money (Kouchaki, Smith-Crowe, Brief, \& Sousa, 2013) that increase instances of dishonesty. Such factors have been demonstrated to shift individuals' attention away from ethical standards, leading to an increase in dishonesty (Pittarello et al., 2015).

The relationship between attention allocation and unethical behavior has real-world implications. Many ethics scandals, from the Ford Pinto controversy in the 1970s to the Enron and WorldCom bankruptcies in the 2000s, have been linked to the failure of CEOs and top managers to pay enough attention to ethical standards (Bazerman \& Tenbrunsel, 2011). Furthermore, at the individual level, it is not uncommon to hear about citizens that have "accidentally" left some expenses out of their total income liability. Overall, these findings suggest that when dishonesty pays, individuals are tempted to ignore, or pay little attention to, undesirable information. However, existing work has yet to provide empirical support for this conclusion.

To address this issue, we employed eyetracking methodologies (Blair, Watson, Walshe, \& Maj, 2009; Fiedler, Glöckner, Nicklisch, \& Dickert, 2013; Glöckner, Fiedler, Hochman, 
Ayal, \& Hilbig, 2012; Glöckner \& Herbold, 2011; Jacob \& Karn, 2003; Poole, Ball, \& Phillips, 2005) and developed a novel experimental task to measure actual cheating, which we call the "Joker task." We propose that when cheating is incentivized, dishonest individuals will pay significantly less attention to undesirable information than to desirable information. Conversely, we hypothesize that honest individuals allocate attention equally to both undesirable and desirable information. We argue that shifting one's attention away from undesirable information can serve as a self-deception strategy that makes it easier to avoid the psychological costs of lying when no justifications are available. This, in turn, enables individuals to profit from dishonesty while simultaneously maintaining a sense of consistency between their behavior and their moral standards (Barkan et al., 2012). Recordings of eye movements represent an "objective and unobtrusive way" (Fiedler et al., 2013, p. 275) of process tracing in decision research (Orquin \& Mueller Loose, 2013; Reisen, Hoffrage, $\&$ Mast, 2008) and reduce potential interference with the decision process (Franco-Watkins \& Johnson, 2011). Measures such as fixation duration and fixation count permit a detailed investigation of process models in several decision-making fields (Fiedler \& Glöckner, 2012). When more attention is allocated to specific information, it denotes the relative importance that such information has in the decision process (Fiedler et al., 2013). A vast array of research findings have indicated that individuals pay more attention to information deemed psychologically prominent, useful, and relevant (Bee, Prendinger, Nakasone, André, \& Ishizuka, 2006; Glöckner et al., 2012; Glöckner \& Herbold, 2011; Halevy \& Chou, 2014). Importantly, scholars have also shown that information search is often goal-directed, with a stronger visual preference toward self-benefiting outcomes (De Dreu \& Boles, 1998; De Dreu \& Carnevale, 2003; Halevy \& Chou, 2014). Indeed, personality factors, motivational states (Balcetis \& Dunning, 2006), and individuals' goals affect gaze behavior through top-down attentional processes (Halevy \& Chou, 2014; Isaacowitz, 2005; Orquin \& Mueller Loose, 2013). As Isaacowitz (2006, p. 68) succinctly stated, "gaze serves as a general motivational role, guiding people towards information that will help them to achieve their goals."

Following this line of research, we suggest that when selfserving choices (e.g., those resulting in valuable payoffs) simultaneously violate moral standards, individuals wishing to increase their financial gains will allocate little attention to undesirable information (e.g., the morally relevant information). This allows them to do wrong without necessarily feeling immoral. Our work provides interesting insights for the literature of behavioral ethics: First, it sheds light on the relationship between attention allocation and unethical behavior. This is important, because attention allocation is considered pivotal in various decision domains (Fiske \& Taylor, 1984). Second, whereas most of the current work has measured unethical behavior in ambiguous situations (see Gino, Norton, \& Ariely, 2010) or when lying cannot be detected (Mazar et al., 2008), we believe that failing to report specific information in certain tasks is an undeniable act, since no justifications for one's behavior are available (Shalvi et al., 2011). This is important, given the debate as to whether many current tasks posited to measure dishonesty do actually measure cheating behavior (Pittarello et al., 2015).

\section{Experiment 1}

\section{Method}

Participants and design A group of 32 university students ( $46 \%$ female, $M_{\text {age }}=23.12$ years, $S D_{\text {age }}=2.09$ ) participated in the experiment. The participants were recruited via advertisements on campus, and each experimental session took approximately $30 \mathrm{~min}$. They earned money on the basis of their payoff in the study, with each participant earning $€ 17.93$ $(\sim 24)$ on average. All of the participants had normal or corrected-to-normal vision and were not colorblind.

Stimuli, apparatus, and procedure Upon arrival at the laboratory, participants read and signed a consent form indicating that an eyetracker would record their eye movements during the experiment. Participants were seated at a distance of $21 \mathrm{in}$. from a Tobii T120 eyetracker with a maximal resolution of 1 , $280 \times 1,024$ pixels. Eye movements were recorded at a sampling rate of $120 \mathrm{~Hz}(\sim 8.33 \mathrm{~ms})$ with an accuracy of $0.45^{\circ}$ of visual angle, and a standard nine-point calibration was used. Fixation durations above $60 \mathrm{~ms}$ were included in the analyses (Komogortsev, Gobert, Jayarathna, Koh, \& Gowda, 2010; Salojärvi et al., 2005). To determine the length of the fixation duration and the number of fixations, two nonoverlapping areas of interests (AOIs) $192 \times 256$ pixels in size and equidistant from the center of the screen, were defined on screen. All stimuli were presented using E-Prime software 1.2 and the TET extension packages for Tobii Studio 1.7. Participants performed the "Joker task," in which they received an initial endowment of $€ 60(\sim 80)$. They were presented with a deck of 120 cards with some of the cards labeled from 1 to 9 (numbers) and some labeled "J" ("Joker"). Stimuli were presented in black-colored uppercase letters on a white background in 22-point Arial font. This ensured that the same amount of information was presented on both sides of the screen during each experimental trial, ruling out the possibility that participants' attention would be captured by contextual features (i.e., the size, color, position, or visual saliency of the stimuli). Participants then read that two cards would be randomly selected from the deck and displayed on the screen simultaneously. One card would be displayed on the right side of the screen and the other would be displayed on the left side. 
If one of the cards was a Joker (on either the left or the right), participants were instructed to click the "L" button on the keyboard. Conversely, if both cards were numbers, participants were instructed to click the " $\mathrm{A}$ " button on the keyboard. Participants also read that they would lose $€ 1$ from their endowment whenever they clicked the " $\mathrm{L}$ " button, and that they would lose no money from their endowment whenever they clicked the "A" button. After clicking either "A" or "L," participants saw their current payoff amount. This procedure was repeated for 120 trials. At the beginning of each trial, a black fixation cross appeared in the center of the screen for 1, $000 \mathrm{~ms}$. This was followed by the presentation of the two cards for an unlimited amount of time (Fig. 1). Recordings of fixation durations began when the fixation cross disappeared from the center of the screen and ended with participants' responses. Thus, participants wishing to maximize their earnings could report that they did not see a Joker when one was indeed present by clicking "A" instead of " $L$," thus avoiding the $€ 1$ loss. In this task, the Joker represented undesirable information, since it was associated with a monetary loss of $€ 1$. The number cards represented desirable information, because they were not associated with monetary loss. Of the 120 trials, 60 trials contained two numbers. The remaining 60 trials contained one Joker and one number. To control for any order effects, in 30 trials the Joker was on the left and the number was on the right, and in the other 30 the Joker was on the right and the number was on the left. The trials were displayed in a random order for each participant. Thus, an honest individual would end the game with $€ 0$. Dishonest participants could lie and maximize their final payoff, up to $€ 60$. Upon completion of the study, participants were paid the appropriate amount, thanked, and debriefed.

\section{Results}

Cheating behavior Participants failed to report the Joker (here: cheating) on $30.4 \%$ of the trials in which one Joker was presented on the screen. Crucially, no mistakes were made in the trials in which two numbers were presented, showing that participants did not make any self-hurting mistakes. Figure 2 shows the frequencies of cheating behavior for each participant.

We conducted a multilevel analysis using R software (version 3.1; R Development Core Team, 2015), and the nlme package (Pinheiro, Bates DebRoy Sarkar \& R Development Core Team, 2015) to explore the distribution of unethical responses over time and to test whether participants were more likely to cheat as their endowment decreased. In doing so, we split the 120 trials into four blocks of 30 trials each (see Shiv, Loewenstein, Bechara, Damasio, \& Damasio, 2005, for a similar procedure). The results revealed a significant effect of the block of trials, $b=$ $.15, S E=.05, z=3.12, p<.001$. Contrasts showed that participants lied more in Blocks 2, 3, and 4 than in Block 1 ( $p$ s $<.01$ for all contrasts), whereas no differences between Blocks 2, 3, and 4 emerged $(p s>.56)$, Overall, this pattern suggests that lying increased as losses increased (for additional details on the analyses, see the Supplemental Materials).

Gaze behavior To test our hypothesis, we focused on the 60 cards containing the Joker, since these were the only trials in which cheating was possible. Fixation durations shorter than $60 \mathrm{~ms}$ were reclassified as nonfixation data points and removed from the analyses (Komogortsev et al., 2010; Salojärvi et al., 2005). The subsequent analyses were conducted on 446 observations for trials containing the Joker on the left and the number on the right, and 476 observations for trials containing the number on the left and the Joker on the right, resulting in a total of 922 observations. Table 1 displays the means and the standard deviations of the fixation durations and counts as a function of AOI and participants' behavior.

Fixation durations As is commonly used in eyetracking research (see Kuperman, Schreuder, Bertram, \& Baayen, 2009; Patla \& Vickers, 1997; Van Assche, Duyck, Hartsuiker, \&

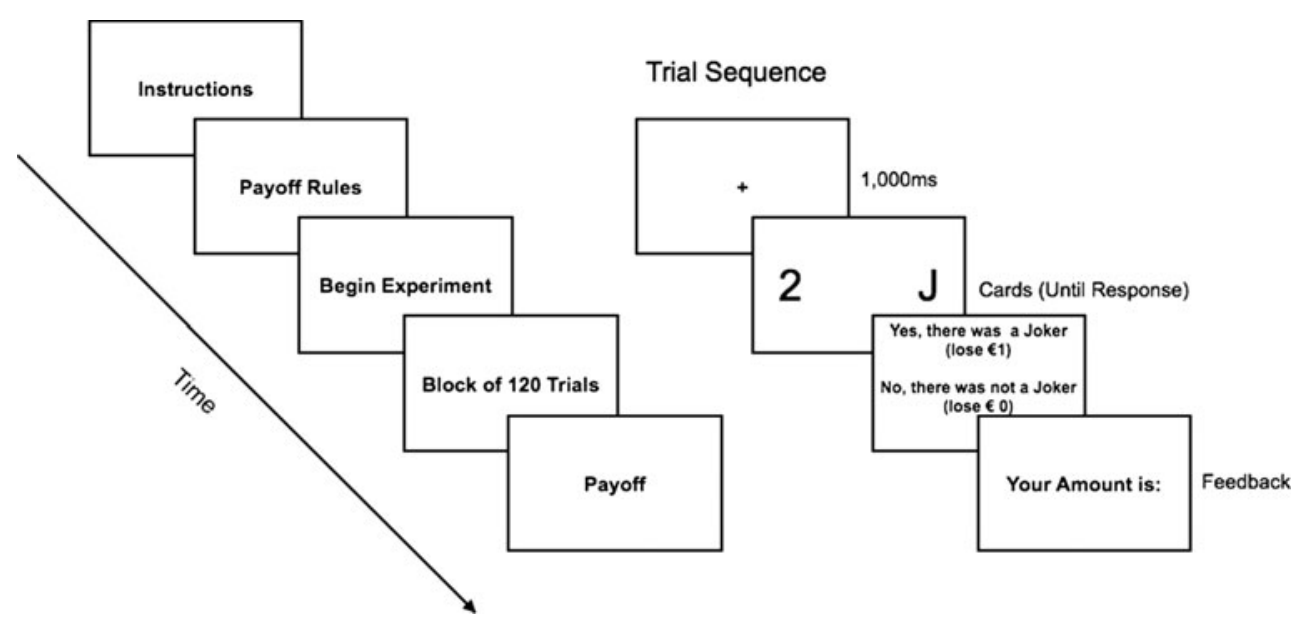

Fig. 1 Procedure for the Joker task 


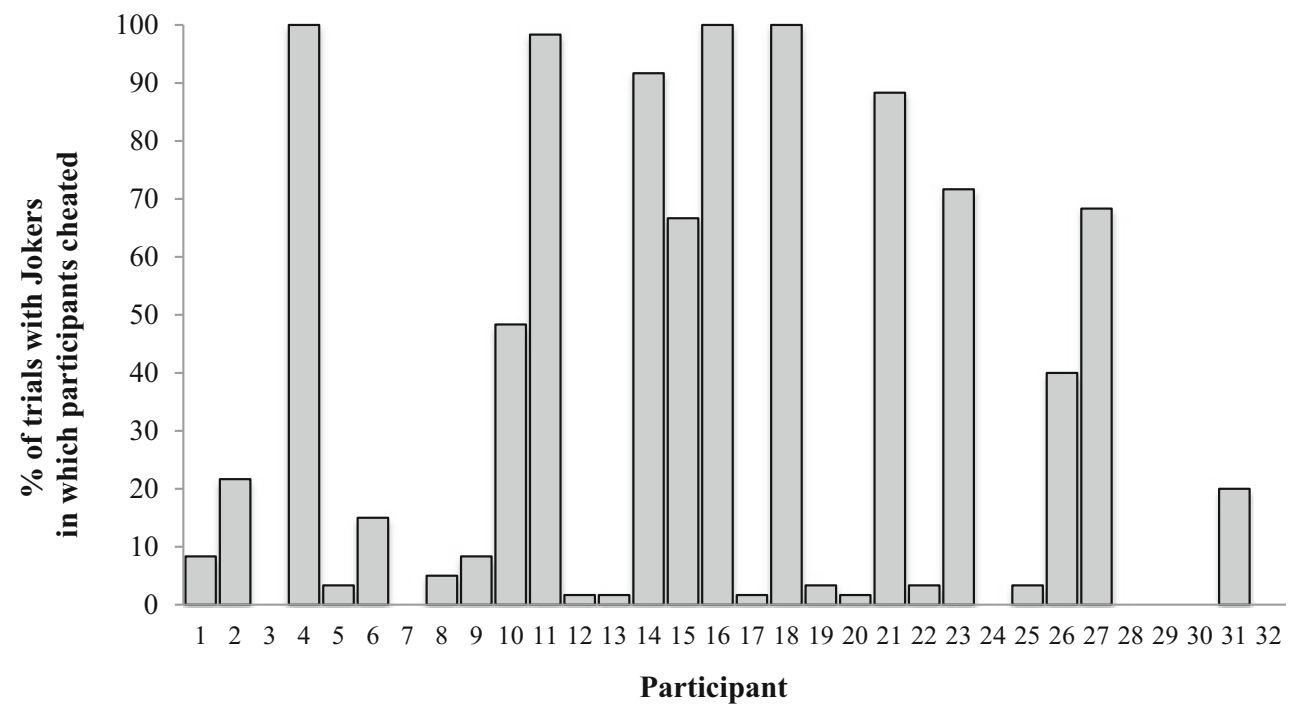

Fig. 2 Percentages of times participants failed to report the Joker when it was presented on the screen

Diependaele, 2009), fixation durations were log-transformed prior to the statistical analyses in order to reduce skewness. This transformation corrected the observed deviation from the normal distribution (from 2.31 to 0.22 ). We conducted multilevel analysis to test whether the AOI (number vs. Joker), participants' behavior (honest vs. dishonest), and their interaction predicted participants' fixation durations (see the Supplemental Materials). As can be seen in Table 2 (top panel), the results showed a significant interaction between AOI and participants' behavior. In comparisons to the trials in which participants behaved honestly, in the trials in which they behaved dishonestly, the results indicated shorter fixation durations on the Joker and longer fixation durations on the number ${ }^{1}$ (see Fig. 3).

Fixation count As for the fixation count, we log-transformed participants' fixation counts in order to satisfy the regression assumption of normality. The distribution of fixation counts was skewed even after the log transformation (from 4.47 to 2.31). Therefore, we removed observations with standardized residuals lower than -2.5 and greater than 2.5 (Baayen, 2008; Roland, Yun, Koenig, \& Mauner, 2012). Once outliers were removed, the distribution of fixation counts approximated the normal curve (skew $=1.01)$. We conducted multilevel analysis to test whether the AOI (number vs. Joker), participants' behavior (honest vs. dishonest), and their interaction predicted participants' numbers of fixations (see the Supplemental Materials). As is shown in Table 2 (bottom panel), the results showed a significant interaction between AOI and participants' behavior. Supporting our hypothesis, in comparison

\footnotetext{
${ }^{1}$ To assess whether fixation durations on the Joker and on the number AOI varied over time on the basis of participants' behavior, we also tested a model including the AOI $\times$ Behavior $\times$ Block of Trials three-way interaction. This model did not reach significance, $\chi^{2}(19)=5.55, p=.14$; therefore the factor Block was subsequently excluded from the analyses.
}

to the trials in which participants behaved honestly, in the trials in which they behaved dishonestly, the results revealed fewer fixations on the Joker ${ }^{2}$ (see Fig. 4).

Relative fixations Finally, we tested relative rather than absolute fixation durations and fixation counts. ${ }^{3}$ Overall, participants had fixations on both types of cards on $25 \%$ of the trials. The results indicated a significantly lower percentage of time spent looking at the Joker in the trials on which participants behaved dishonestly than in the trials on which they behaved honestly, $b=-11.24, S E=4.47, t=-2.52, p=.01$. The same analysis was conducted for the relative number of fixations made on the Joker. In line with our predictions, the results showed a lower percentage of time spent looking at the Joker in the trials on which participants behaved dishonestly than in the trials on which they behaved honestly, $b=-11.58$, $S E=4.39, t=-2.64, p<.01$.

\section{Discussion}

In the trials on which participants cheated, they allocated significantly less attention to undesirable information (the Joker card) than when they behaved honestly. However, one might argue that the unethical responses could have resulted from participants mistakenly failing to report that the Joker card was present, rather than from the motivation to benefit from dishonesty. To rule out this possibility, we conducted an additional behavioral experiment, without tracking participants' eye movements.

\footnotetext{
${ }^{2}$ As for fixation durations, the AOI $\times$ Behavior $\times$ Block of Trials threeway interaction predicting fixation counts did not reach significance, $\chi^{2}(19)=2.10, p=.55$.

${ }^{3}$ The relative fixation duration (or fixation count) for the Joker AOI was computed for each trial by dividing the length of the fixation durations (fixation counts) on the Joker card by the sum of the fixation durations (fixation count) on both cards.
} 
Table 1 Mean fixation durations and fixation counts based on area of interest (AOI) and participants' behavior (standard deviations are in parentheses)

\begin{tabular}{llll}
\hline Measure & AOI & Honest trials & Dishonest trials \\
\hline Fixation durations (log-transformed) & Joker & $5.33(0.65)$ & $5.25(0.69)$ \\
& Number & $5.13(0.61)$ & $5.27(0.65)$ \\
Fixation count (log-transformed) & Joker & $.36(.47)$ & $.23(.39)$ \\
& Number & $.30(.44)$ & $.37(.46)$ \\
\hline
\end{tabular}

\section{Experiment 2}

\section{Method}

Participants and design A group of 24 university students (70\% female, $M_{\text {age }}=26.66$ years, $\left.S D_{\text {age }}=3.67\right)$ completed the same tasks described in Experiment 1, with the following exceptions: In Experiment 2, we removed the financial incentives to cheat and paid participants only on the basis of the accuracy of their responses. Specifically, participants were informed that they would receive $€ 5$ if they answered correctly on one trial selected randomly at the end of the experiment.

\section{Results}

Participants answered correctly on $99.5 \%$ of the trials. In the trials on which participants answered incorrectly, the proportion of times that participants reported a Joker when a Joker was not presented on the screen $(42.9 \%)$ did not differ from the proportion of times when participants failed to report a Joker when the Joker was indeed present (57.1\%), $p>.25$. Comparisons between Experiments 1 and 2 should be done with caution, since the two experiments were conducted at different times. Taking this into account, a chi-square analysis showed that the proportion of self-serving choices (i.e., failures to report the Joker) was significantly higher when

Table 2 Regression coefficients for a multilevel analysis predicting participants' fixation durations (top panel) and fixation counts (bottom panel) on the Joker and number areas of interest (AOIs)

\begin{tabular}{lcccl}
\hline & $b$ & $S E$ & $t$ & $p$ \\
\hline $\begin{array}{l}\text { Fixation durations (log-transformed) } \\
\quad\end{array}$ & 5.22 & 0.06 & 82.88 & $<.001$ \\
$\quad$ Intercept & -.14 & .08 & -1.72 & .08 \\
Participants' behavior & -.25 & .04 & -5.33 & $<.001$ \\
AOI & .26 & .09 & 2.90 & $<.05$ \\
Participants' behavior $\times$ AOI & & & & \\
Fixation count (log-transformed) & & & & \\
Intercept & 0.40 & 0.03 & 11.01 & $<.001$ \\
Participants' behavior & -.16 & .05 & -2.80 & $<.05$ \\
AOI & -.05 & .03 & -1.55 & .12 \\
Participants' behavior $\times$ AOI & .19 & .07 & 3.02 & $<.05$ \\
\hline
\end{tabular}

cheating was incentivized (Exp. 1) than when it was not (Exp. 2), $\chi^{2}(1)=439.00, p<.001$.

\section{General discussion}

We showed that when dishonesty is incentivized, individuals motivated to maximize their gains direct their attention away from undesirable information. In the Joker task, we asked participants to report whether or not one of two cards presented on the screen was a Joker (reporting a Joker meant losing $€ 1)$. We found that when participants falsely reported not seeing a Joker on a certain trial, they paid significantly less attention to the Joker card than when they honestly reported seeing a Joker on another trial. Importantly, the same pattern of mistakes did not emerge when accuracy was incentivized rather than lying (Exp. 2). Our results suggest that directing attention away from undesirable information might serve as a selfdeception strategy that allows individuals to benefit from dishonesty while limiting their ethical liability. In addition, we feel that our findings are especially interesting because participants were aware that their behavior was being tracked. We propose, carefully, that this last point might indicate that individuals appeared to be more influenced by their motivation to avoid losing money than by their knowledge that their eye movements were being monitored. Future research will be needed to provide stronger support for our findings. Additionally, it would be interesting to test whether the decision to allocate greater attention to the number than to the Joker represents a conscious strategy to fool the experimenter, or whether this behavior is accentuated among individuals less inclined to follow the rules (i.e., higher levels of moral disengagement).

We acknowledge that our method has limitations: First, although we propose that this shift of attention permits individuals to do wrong without directly confronting their dishonesty, future research should include proximal measures of self-concept following the decision to cheat, to further validate this conclusion. Second, our results cannot fully disentangle the causal direction between eye movements and unethical behavior. Although we propose that the motive to secure self-serving financial gains represents a top-down process leading individuals to shift their attention away from undesirable information, it 


\section{Fixation Durations}

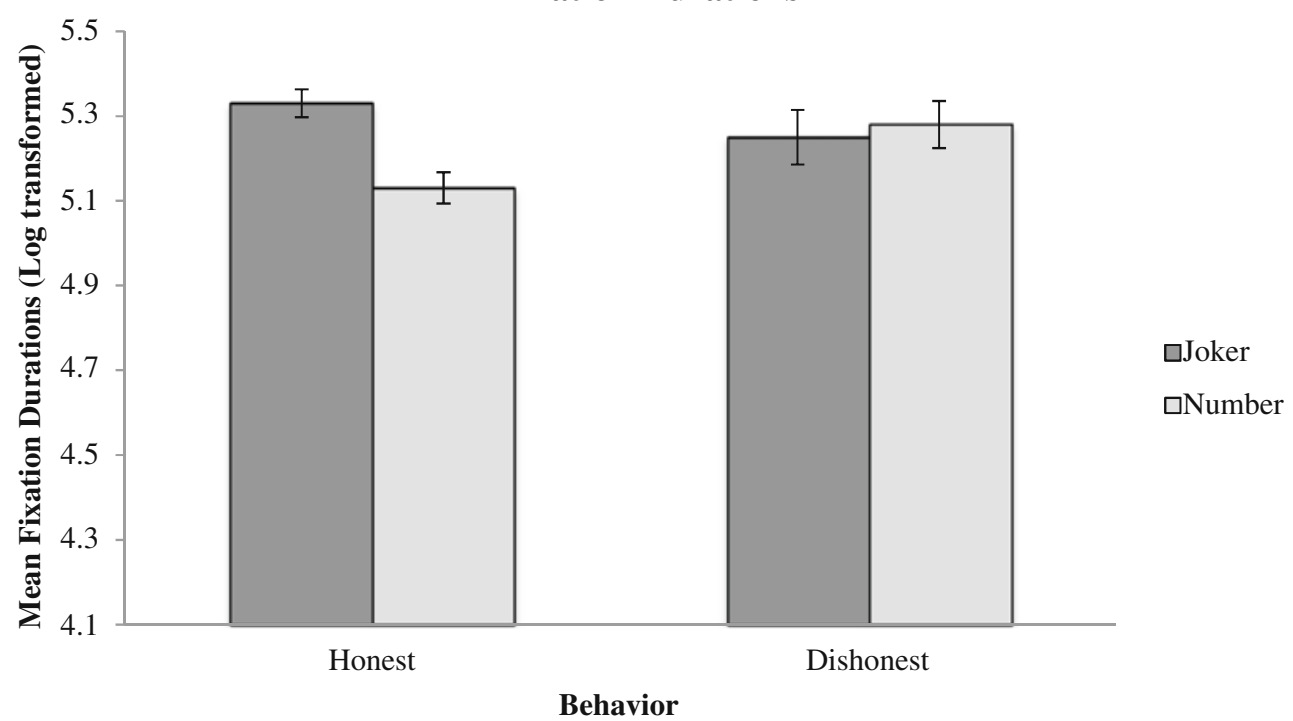

Fig. 3 Participants' fixation durations (log-transformed) as a function of area of interest (number vs. Joker) and participants' behavior (honest vs. dishonest). Error bars represent standard errors

could also be argued that more desirable information captures individual attention, in turn shaping dishonest responses. For instance, varying the monetary loss associated with the Joker card (high vs. low) and assessing whether this affected the amount of attention allotted to the card across trials could help shed additional light on the direction of causality. Another interesting avenue for future research would be to explore whether the shift of attention toward the favored and more profitable option occurs at the beginning of each trial (therefore indicating an information avoidance strategy) or emerges later over time. This phenomenon is defined as the gaze-cascade effect
(Fiedler \& Glöckner, 2012), since it refers to individuals' tendency to shift attention toward the chosen option over the course of the decision-making process (see also Shimojo, Simion, Shimojo, \& Scheier, 2003). Such finegrained analysis can shed further light on the relationship between gaze and unethical behavior. Finally, the participants in our experiment lied to avoid financial loss. An interesting topic for future research would be to test whether the gaze patterns that we found extend to social situations in which the motivation to allocate less attention to undesirable information is not related to financial benefits (e.g., athletes refraining from reporting the use of

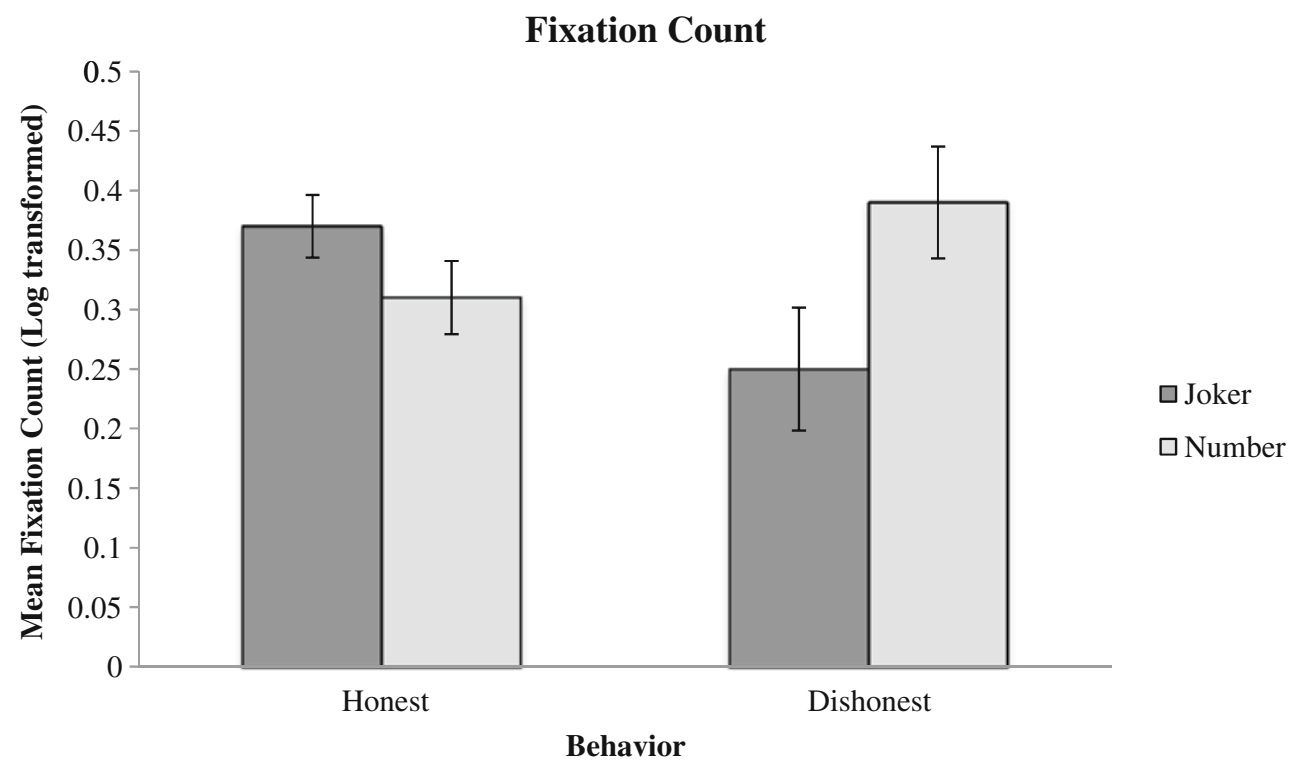

Fig. 4 Participants' fixation counts as function of area of interest (number vs. Joker) and participants' behavior (honest vs. dishonest). Error bars represent standard errors 
banned substances by their teammates in order to avoid their team losing its ranking in the league).

By providing evidence that self-serving dishonesty leads individuals to pay less attention to undesirable information, we very cautiously hint toward a potential approach for decreasing unethical behavior: encouraging people in moral dilemmas to pay more attention to undesirable information. Doing so might reduce instances of cheating and foster greater adherence to ethical standards.

\section{References}

Baayen, R. H. (2008). Analyzing linguistic data: A practical introduction to statistics using $R$. Cambridge, UK: Cambridge University Press.

Balcetis, E., \& Dunning, D. (2006). See what you want to see: Motivational influences on visual perception. Journal of Personality and Social Psychology, 91, 612-625.

Barkan, R., Ayal, S., Gino, F., \& Ariely, D. (2012). The pot calling the kettle black: Distancing response to ethical dissonance. Journal of Experimental Psychology: General, 141, 757-773.

Bazerman, M. H., \& Tenbrunsel, A. E. (2011). Blind spots: Why we fail to do what's right and what to do about it. Princeton, NJ: Princeton University Press.

Bee, N., Prendinger, H., Nakasone, A., André, E., \& Ishizuka, M. (2006). Autoselect: What you want is what you get: Real-time processing of visual attention and affect. In E. André (Ed.), Perception and interactive technologies (Lecture Notes in Computer Science (Vol. 4021, pp. 40-52). Berlin, Germany: Springer.

Blair, M. R., Watson, M. R., Walshe, R. C., \& Maj, F. (2009). Extremely selective attention: Eye-tracking studies of the dynamic allocation of attention to stimulus features in categorization. Journal of Experimental Psychology: Learning, Memory, and Cognition, 35, 1196-1206. doi:10.1037/a0016272

De Dreu, C. K., \& Boles, T. L. (1998). Share and share alike or winner take all? The influence of social value orientation upon choice and recall of negotiation heuristics. Organizational Behavior and Human Decision Processes, 76, 253-276.

De Dreu, C. K., \& Carnevale, P. J. (2003). Motivational bases of information processing and strategy in conflict and negotiation. Advances in Experimental Social Psychology, 35, 235-291.

Fiedler, S., \& Glöckner, A. (2012). The dynamics of decision making in risky choice: An eye-tracking analysis. Frontiers in Psychology, 3, 335. doi:10.3389/fpsyg. 2012.00335

Fiedler, S., Glöckner, A., Nicklisch, A., \& Dickert, S. (2013). Social value orientation and information search in social dilemmas: An eyetracking analysis. Organizational Behavior and Human Decision Processes, 120, 272-284.

Fiske, S. T., \& Taylor, S. E. (1984). Social cognition. New York, NY: Random House.

Franco-Watkins, A. M., \& Johnson, J. G. (2011). Decision moving window: Using interactive eye tracking to examine decision processes. Behavior Research Methods, 43, 853-863. doi:10.3758/s13428011-0083-y

Gino, F., Norton, M. I., \& Ariely, D. (2010). The counterfeit self the deceptive costs of faking it. Psychological Science, 21, 712720.

Glöckner, A., Fiedler, S., Hochman, G., Ayal, S., \& Hilbig, B. E. (2012). Processing differences between descriptions and experience: A comparative analysis using eye-tracking and physiological measures. Frontiers in Psychology, 3, 173. doi: 10.3389/fpsyg.2012.00173

Glöckner, A., \& Herbold, A. K. (2011). An eye-tracking study on information processing in risky decisions: Evidence for compensatory strategies based on automatic processes. Journal of Behavioral Decision Making, 24, 71-98.

Halevy, N., \& Chou, E. Y. (2014). How decisions happen: Focal points and blind spots in interdependent decision-making. Journal of Personality and Social Psychology, 106, 398-417.

Isaacowitz, D. M. (2005). The gaze of the optimist. Personality and Social Psychology Bulletin, 31, 407-415.

Isaacowitz, D. M. (2006). Motivated gaze the view from the gazer. Current Directions in Psychological Science, 15, 68-72.

Jacob, R. J., \& Karn, K. S. (2003). Eye tracking in human-computer interaction and usability research: Ready to deliver the promises. Mind, 2, 573-605.

Komogortsev, O. V., Gobert, D. V., Jayarathna, S., Koh, D. H., \& Gowda, S. M. (2010). Standardization of automated analyses of oculomotor fixation and saccadic behaviors. IEEE Transactions in Biomedical Engineering, 57, 2635-2645.

Kouchaki, M., Smith-Crowe, K., Brief, A. P., \& Sousa, C. (2013). Seeing green: Mere exposure to money triggers a business decision frame and unethical outcomes. Organizational Behavior and Human Decision Processes, 121, 53-61.

Kuperman, V., Schreuder, R., Bertram, R., \& Baayen, R. H. (2009). Reading polymorphemic Dutch compounds: Toward a multiple route model of lexical processing. Journal of Experimental Psychology: Human Perception and Performance, 35, 875-895. doi: $10.1037 / \mathrm{a} 0013484$

Mazar, N., Amir, O., \& Ariely, D. (2008). The dishonesty of honest people: A theory of self-concept maintenance. Journal of Marketing Research, 45, 633-644.

Orquin, J. L., \& Mueller Loose, S. M. (2013). Attention and choice: A review on eye movements in decision making. Acta Psychologica, 144, 190-206.

Patla, A. E., \& Vickers, J. N. (1997). Where and when do we look as we approach and step over an obstacle in the travel path? NeuroReport, 8, 3661-3665.

Pinheiro, J., Bates, D., DebRoy, S., Sarkar, D., \& R Development Core Team. (2015). nlme: Linear and nonlinear mixed effects models ( $R$ package version 3.1-120). Retrieved from http://CRAN.R-project. org $/$ package $=$ nlme

Pittarello, A., Leib, M., Gordon-Hecker, T., \& Shalvi, S. (2015). Justifications shape ethical blind spots. Psychological Science, 26, 794-804.

Poole, A., Ball, L. J., \& Phillips, P. (2005). In search of salience: A response-time and eye-movement analysis of bookmark recognition. People and Computers, 18, 363-378.

R Development Core Team. (2015). $R$ : A language and environment for statistical computing. Vienna, Austria: R Foundation for Statistical Computing. Retrieved from www.R-project.org

Reisen, N., Hoffrage, U., \& Mast, F. W. (2008). Identifying decision strategies in a consumer choice situation. Judgment and Decision Making, 3, 641-658.

Roland, D., Yun, H., Koenig, J. P., \& Mauner, G. (2012). Semantic similarity, predictability, and models of sentence processing. Cognition, 122, 267-279.

Salojärvi, J., Puolamäki, K., Simola, J., Kovanen, L., Kojo, I., \& Kaski, S. (2005). Inferring relevance from eye movements: Feature extraction (Technical Report). Publications in Computer and Information Science, Espoo, Finland: PASCAL EU Network of Excellence Challenge.

Shalvi, S., Dana, J., Handgraaf, M. J., \& De Dreu, C. K. (2011). Justified ethicality: Observing desired counterfactuals modifies ethical perceptions and behavior. Organizational Behavior and Human Decision Processes, 115, 181-190. 
Shimojo, S., Simion, C., Shimojo, E., \& Scheier, C. (2003). Gaze bias both reflects and influences preference. Nature Neuroscience, 6 , 1317-1322.

Shiv, B., Loewenstein, G., Bechara, A., Damasio, H., \& Damasio, A. R. (2005). Investment behavior and the negative side of emotion. Psychological Science, 16, 435-439.

Shu, L. L., Gino, F., \& Bazerman, M. H. (2011). Dishonest deed, clear conscience: When cheating leads to moral disengagement and motivated forgetting. Personality and Social Psychology Bulletin, 37, 330-349.
Tenbrunsel, A. E., \& Messick, D. M. (2004). Ethical fading: The role of self-deception in unethical behavior. Social Justice Research, 17, 223-236.

Van Assche, E., Duyck, W., Hartsuiker, R. J., \& Diependaele, K. (2009). Does bilingualism change native-language reading? Cognate effects in a sentence context. Psychological Science, 20, 923-927. doi:10. 1111/j.1467-9280.2009.02389.x

Zhong, C. B. (2011). The ethical dangers of deliberative decision-making. Administrative Science Quarterly, 56, 1-25. 